DOI: 10.2478/romneu-2014-0007

\title{
Cladophialophora bantiana brain abscess masquerading cerebral tuberculoma in an immunocompetent host
}

\author{
Amit Agrawal ${ }^{1}$, Vissa Shanthi², K.V. Murali Mohan ${ }^{3}$, Kishor V. Hegde ${ }^{4}$, \\ Umamaheshwar Reddy V. ${ }^{5}$ \\ ${ }^{1}$ Professor of Neurosurgery, Department of Neurosurgery, Narayana Medical College Hospital, \\ Chinthareddypalem, Nellore, Andhra Pradesh (India) \\ ${ }^{2}$ Associate Professor of Pathology, Department of Pathology, Narayana Medical College Hospital, \\ Chinthareddypalem, Nellore, Andhra Pradesh (India) \\ ${ }^{3}$ Professor of Pathology, Department of Pathology, Narayana Medical College Hospital, \\ Chinthareddypalem, Nellore, Andhra Pradesh (India) \\ ${ }^{4}$ Professor of Radiology, Department of Radiology, Narayana Medical College Hospital, \\ Chinthareddypalem, Nellore, Andhra Pradesh (India) \\ ${ }^{5}$ Assistant Professor of Radiology, Department of Radiology, Narayana Medical College Hospital, \\ Chinthareddypalem, Nellore, Andhra Pradesh (India)
}

\begin{abstract}
Phaeohyphomycosis is a term that collectively describes fungal infections caused by moulds and yeasts that have brown-pigmented cell walls (due to the presence of melanin). We report a case of 45 year female who had multiple coalescing lesions in the right basal ganglionic and thalamic region. Based on the imaging and investigation findings a diagnosis of cerebral tuberculoma was suspected. Histopathology of the excised specimen showed brown colored fungal hyphae surrounded by neutrophilic infiltrate. A diagnosis of phaeohyphomycosis caused by Cladophialophora bantiana was made and accordingly antifungal treatment was started. Brain abscess caused by Cladophialophora bantiana in an immunocompetent host is relatively
\end{abstract}

uncommon and usually associated with overall high mortality. The best outcomes have been reported in patients who receive both surgical excision of the abscess followed by systemic antifungal therapy. In view of its rarity of these lesions preoperative diagnosis is difficult particularly in an immunocompetent host and absence of other risk factors.

Key words: Phaeohyphomycosis, cerebral, fungal infection, brain

\section{Introduction}

Phaeohyphomycosis infections is caused by dematiaceous fungi i.e., fungi that contain melanin in their cell walls. 1-3 Cladophialophora bantiana usually causes brain abscess in immunocompromised hosts. (1-4) Brain abscess caused by Cladophialophora bantiana in an immunocompetent host is relatively 
uncommon. (1-3) In present article we discuss a case of brain abscess caused Cladophialophora bantiana in an immunocompetent host which was masquerading cerebral tuberculoma.

\section{Case report}

A 45 year female presented with the history of sudden onset of loss of consciousness for 10 minutes of 1 day back. While she regained the consciousness there was weakness of left upper and lower limbs, slurring of speech, difficulty in walking, moderate headache and multiple episodes of vomiting. There was no history of fever or seizures. There was no history of diabetes mellitus or any major illness in the past. At the time of examination she was conscious, dull and was obeying commands. Pupils were bilateral equal and reacting to light. Fundus showed mild papilledema and there was left upper motor neuron type of facial nerve palsy. There was weakness of left upper and lower limbs of grade 2/5 with exaggerated deep tendon reflexes. Left plantar reflex was extensor and right was flexor. All the blood investigations were normal except raised ESR (46 $\mathrm{mm}$ in 1st hour) and leukocytosis $(18,000 / \mathrm{mm} 3)$. Test for HIV was negative. Chest $\mathrm{x}$-ray was normal. CT scan showed multiple coalescing lesions in the right basal ganglionic and thalamic region with significant perilesional edema and mass effect (Figure 1). Based on the imaging and investigation findings a diagnosis of cerebral tuberculoma was suspected and she was started on ATT and steroids. On 3rd admission she suddenly lapsed into altered sensorium (GCS-E1V1M2), right pupil became dilated and non-reacting. An urgent MRI showed increase in cerebral edema and mass effect (Figure 2). The patient was taken for emergency decompressive right frontal craniotomy and biopsy of the lesions. There was illdefined lesion with thin walled capsule with caseating material and yellowish nonfoul smelling pus. Again an intraoperative diagnosis was tubercular abscess. Following surgery the patient was kept on elective ventilation. She was continued on antiedema measures, anti-epileptics and was continued on ATT. There was no improvement in her condition. Histopathology showed brown colored fungal hyphae surrounded by neutrophilic infiltrate. Septate fungal hyphae were surrounded by neutrophilic infiltrate (Figure 3). A diagnosis of phaeohyphomycosis caused by Cladophialophora bantiana was made and accordingly antifungal treatment was started. However she did not respond to treatment and succumbed to the infection.

\section{Discussion}

Phaeohyphomycosis is a term that collectively describes fungal infections caused by moulds and yeasts that have brown-pigmented cell walls (due to the presence of melanin). (4) 


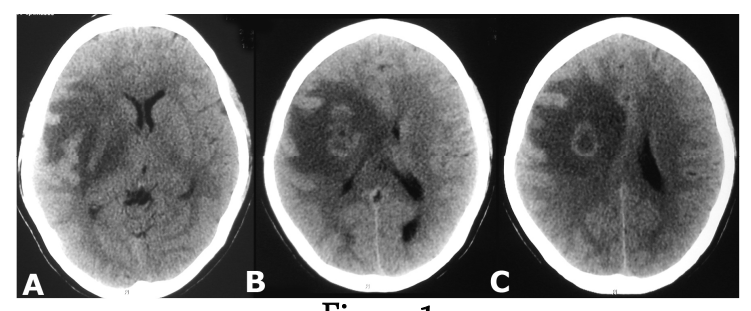

Figure 1

(A, B and C) CT scan brain showing multiple coalescing lesions in the right basal ganglionic and thalamic region with minimal peripheral enhancement, significant mass effect and midline shift

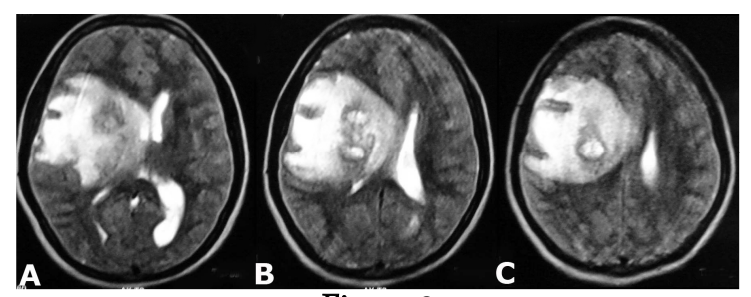

Figure 2

(A, B and C) MRI T2W sequences showing multiple ring shaped hyerintense lesions in right

basal ganglionic and thalamic region with surrounding hypointense rim, extensive peri-lesional edema and mass effect

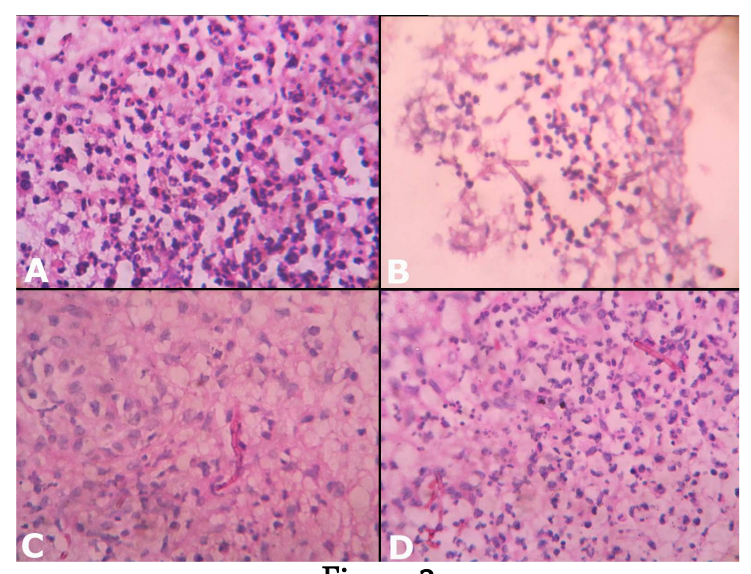

Figure 3

(A and B) Brown colored fungal hyphae surrounded by neutrophilic infiltrate ( $\mathrm{H} \& \mathrm{E}, \mathrm{x} 400),(\mathrm{C}$ and $\mathrm{D})$ septate fungal hyphae surrounded by neutrophilic infiltrate (PAS, $\mathrm{x} 400$ )

Cladophialophora bantiana has been implicated as a leading cause of cerebral phaeohyphomycosis, and is a soil-based neurotropic fungus, which has affinity to glial tissue. (2) Although not clearly established, most probably the portal of entry is through respiratory tract. $(2,3,5$, 6) However, in the majority of patients of cerebral phaeohyphomycosis there may not be any evidence of sinus or lung disease. $(7,8)$ The exact pathogenesis of primary cerebral phaeohyphomycosis is presently unknown 9 and it has been suggested that the pathogenicity is primarily due to melanin (melanin is present in their cell walls and imparts the characteristic dark color to their conidia and hyphae) which scavenges free radicals produced by phagocytic cells. $(2,10,11)$ Clinically phaeohyphomycosis can present from solitary subcutaneous nodules to lifethreatening infections, brain abscess and disseminated disease. (3) As was seen in present case features of raised intracranial pressure (headache) followed by focal neurological deficits and/or generalized seizures are the most common presentation of Cladophialophora brain abscess. (2, 3) Because of its rarity it is difficult to make a pre-operative diagnosis of cerebral phaeohyphomycosis especially in an immunocompetent host. $3 \mathrm{~A}$ number of commoner disorders (i.e. tuberculosis, cysticercosis, demyelinating disorders, pyogenic abscess, toxoplasmosis, fungal infections, neurosyphilis, sarcoidosis, Behcet disease, radiation encephalopathy, cerebral venous thrombosis and vasculitic disorders) including the immune status of the patient needs to be considered in the 
differential diagnosis of ring-enhancing lesions on neuroimaging. (12-14) As we confronted in the case, presently there are no specific initial clinical or laboratory feature that makes a preoperative fungal abscess diagnosis possible. $(2,3,15)$ The diagnosis is only possible once the tissue is submitted for the histopathological or microbiological examination. (2, 3) Because of the rarity of cerebral phaeohyphomycosis there are no standard guidelines for therapy and not many clinical trials comparing different treatment regimens. (2) The best outcomes were seen in patients who receive both surgical excision of the abscess followed by systemic antifungal therapy. $(2,5,15)$ The combination of amphotericin B, 5-FC, and itraconazole has been suggested to improve survival; however only in few cases this triple combination is used. $(1,16-18)$ Newer anti-fungal agents (voriconazole and itraconazole) have been found to be effective for the management of these unusual lesions. $(19,20)$

\section{Conclusion}

In summary, cerebral phaeohyphomycosis is associated with overall high mortality (around $70 \%)(2,3$, 15, 21) and the Cladosporium bantianum species has been reported particularly to be more virulent with poorer outcome. 1 In view of its rarity of these lesions preoperative diagnosis is difficult particularly in an immunocompetent host and absence of other risk factors. Till we find a better ways to diagnose such cases in advance we need to depend on histopathology and microbiological investigations of the tissue.

Address for correspondence:

Dr. Amit Agrawal

Professor of Neurosurgery

Department of Neurosurgery

Narayana Medical College Hospital

Chinthareddypalem

Nellore-524003

Andhra Pradesh (India)

Email: dramitagrawal@gmail.com

dramit_in@yahoo.com

Mobile: +91-8096410032

\section{References}

1.Borkar SA, Sharma MS, Rajpal G, Jain M, Xess I, Sharma BS. Brain abscess caused by Cladophialophora Bantiana in an immunocompetent host: need for a novel cost-effective antifungal agent. Indian journal of medical microbiology 2008;26:271-274.

2.Revankar SG, Sutton DA, Rinaldi MG. Primary central nervous system phaeohyphomycosis: a review of 101 cases. Clinical infectious diseases : an official publication of the Infectious Diseases Society of America 2004;38:206-216.

3.George IA, Mathews MS, Karthik R, et al. Fatal cerebral abscess caused by Cladophialophora bantiana. The Journal of the Association of Physicians of India 2008;56:470-472.

4.Surash S, Tyagi A, De Hoog GS, Zeng JS, Barton RC, Hobson RP. Cerebral phaeohyphomycosis caused by Fonsecaea monophora. Medical mycology 2005;43:465472.

5.Levin TP, Baty DE, Fekete T, Truant AL, Suh B. Cladophialophora bantiana brain abscess in a solidorgan transplant recipient: case report and review of the literature. Journal of clinical microbiology 2004;42:43744378.

6.Goel A, Satoskar A, Desai AP, Pandya SK. Brain abscess caused by Cladosporium trichoides. British journal of neurosurgery 1992;6:591-593.

7.Sutton DA, Slifkin M, Yakulis R, Rinaldi MG. U.S. case report of cerebral phaeohyphomycosis caused by Ramichloridium obovoideum (R. mackenziei): criteria for identification, therapy, and review of other known 
DOI: $10.2478 /$ romneu-2014-0007

dematiaceous neurotropic taxa. Journal of clinical microbiology 1998;36:708-715.

8.Horré R, De Hoog G. Primary cerebral infections by melanized fungi: a review. Stud Mycol 1999;43:93.

9.Brown JW, Nadell J, Sanders CV, Sardenga L. Brain abscess caused by Cladosporium trichoides (Bantianum): a case with paranasal sinus involvement. Southern medical journal 1976;69:1519-1521.

10.Casadevall A, Rosas AL, Nosanchuk JD. Melanin and virulence in Cryptococcus neoformans. Current opinion in microbiology 2000;3:354-358.

11.Dixon DM, Polak A, Szaniszlo PJ. Pathogenicity and virulence of wild-type and melanin-deficient Wangiella dermatitidis. Journal of medical and veterinary mycology : bi-monthly publication of the International Society for Human and Animal Mycology 1987;25:97106.

12.Garg RK, Sinha MK. Multiple ring-enhancing lesions of the brain. Journal of postgraduate medicine 2010;56:307-316.

13.Cortese I, Nath A. Case 11: a young woman with ring-enhancing brain lesions. MedGenMed : Medscape general medicine 2006;8:3.

14.Omuro AM, Leite CC, Mokhtari K, Delattre J-Y. Pitfalls in the diagnosis of brain tumours. Lancet neurology 2006;5:937-948.
15.Deb S, Khan AK, Debasish B, Subroto B. Intracranial necrotizing granuloma caused by Cladophialophora bantiana. Neurology India 2005;53:335-336.

16.McGinnis MR, Pasarell L. In vitro evaluation of terbinafine and itraconazole against dematiaceous fungi. Medical mycology 1998;36:243-246.

17.Walsh TJ, Goodman JL, Pappas P, et al. Safety, tolerance, and pharmacokinetics of high-dose liposomal amphotericin B (AmBisome) in patients infected with Aspergillus species and other filamentous fungi: maximum tolerated dose study. Antimicrobial agents and chemotherapy 2001;45:3487-3496.

18.Sharkey PK, Graybill JR, Rinaldi MG, et al. Itraconazole treatment of phaeohyphomycosis. Journal of the American Academy of Dermatology 1990;23:577586.

19.Fica A, Diaz M-C, Luppi M, et al. Unsuccessful treatment with voriconazole of a brain abscess due to Cladophialophora bantiana. Scandinavian journal of infectious diseases 2003;35:892-893.

20.Lyons MK, Blair JE, Leslie KO. Successful treatment with voriconazole of fungal cerebral abscess due to Cladophialophora bantiana. Clinical neurology and neurosurgery 2005;107:532-534.

21.Jayakeerthi SR, Dias M, Nagarathna S, Anandh B, Mahadevan A, Chandramuki A. Brain abscess due to Cladophialophora bantiana. Indian journal of medical microbiology 2004;22:193-195. 